\title{
Real-Time Polymerase Chain Reaction Detection of Trichomonas vaginalis from vaginal swabs: Validation of a Diagnostic Method and Preliminary Epidemiological Application
}

\author{
Carlo Mengoli,', Maria Angela Biasolo',,2, Antonietta Cavallaro', Giorgio Palu', \\ Annalisa Trevisan' \\ 'Service of Microbiology and Virology, Azienda Ospedaliera di Padova, Italy \\ ${ }^{2}$ Department of Histology, Microbiology and Medical Biotechnology, University of Padua, Italy
}

Key Words: Trichomonas vaginalis, real-time PCR, vaginal swab

\section{SUMMARY \\ Background}

Frichomonas vaginalis is the most common nonviral sexually trasmitted diseases (STDs) agent. For females, the diagnostic gold standard is the culture of vaginal swab, which is labour-exacting. The direct microscopic examination of vaginal secretions is the most used approach, but its sensitivity depends on the skill of the observer.

\section{Objectives}

We evaluated an original real-time TaqMan-based Polymerase Chain Reaction (PCR) technique. The scope of the study was to confirm the effectiveness of the molecular approach in a clinical context and to explore its relevance to an epidemiological investigation.

\section{Study Design}

a $\beta$-tubulin gene was chosen as target sequence. The assay was designed to-exploit the quantitative potential of the TaqMan procedure. The population sample was 583 adult females presenting at the Service from January 2005 to December 2005. Three vaginal swabs were collected from each patient, one for wet mount microscopy, one for broth culture, and one for the molecular assay.

\section{Results}

The prevalence was 3.3\% (culture), 3.1\% (microscopy), 3.8\% (PCR).An-excess risk was detected in the immigrant population (risk ratio by PCR $=28$ ).

\section{Conclusions}

The molecular approach was the most accurate way to detect the protozoon. The real-time PCR is convenient in a busy laboratory, provided the necessary equipment is available, and it is suitable for epidemiological investigation,

\section{Received April 8, 2009}

Accepted April 2I, 2009

\section{INTRODUCTION}

Trichomonas vaginalis is the most common nonviral sexually trasmitted diseases (STDs) agent on a world scale. One hundred and eighty millions new infections are estimated every year (20). According to the population studied, the prevalence of infection in females varies from 5 to $50 \%$ in patients attending sexually transmitted disease (STD) clinics (16). The prevalence is rapidly growing, particularly in Sub-Saharan Africa, SouthEast Asia, and East Europe. The incidence is highest among women with multiple sexual partners and in groups with high rates of other STDs
(7). This agent causes trichomoniasis and has been linked to preterm birth, acquisition of human immunodeficiency virus, infertility, and nongonococcal urethritis $(3,19)$. Patients harboring the protozoon are at risk of, and should be screened for, other pathogens, such as Neisseria gonorrhoeae, Chlamydia trachomatis, and HIV. These can be more worrisome, even if clinically silent at the time of clinical examination. In clinical practice the direct microscopic examination of vaginal secretions using the wet mount technique is the most commonly used approach. To identify the protozoon it is necessary to recur to an expert

\section{Corresponding author: Carlo Mengoli}

Service of Microbiology and Virology, Azienda Ospedaliera di Padova - Via Giustiniani I, 35I 28 Padova, Italy

Department of Histology, Microbiology and Medical Biotechnology, University of Padua, Via Gabelli 63, 35 I 28 Padova, Italy

Tel: 0390498272345 - 03904982123052 - Fax: 0390498272355 - E-mail: carlo.mengoli@unipd.it 
microscopist. As with all microscopic diagnoses, the accuracy of the direct examination is highly dependent on the skill and diligence of the observer. The sensitivity of the direct examination depends strictly on timeliness of the microscopic reading which must be done immediately after the swab collection. Indeed T.vaginalis quickly loses its motility and cannot be distinguished from white blood cells. Culture is still regarded as the "gold standard" for determining the performance of other diagnostic tests, but it is not clear which medium formulation and culture system is best for T.vaginalis. Moreover, all liquid culture systems for T.vaginalis require repeated media sampling and examination up for seven days, making the procedure unpractical for population screening programs (14).

A DNA $2.3 \mathrm{~kb}$ probe was cloned by Rubino et al. (18) for detection of T.vaginalis by a dot blot hybridization technique. A molecular PCR-based approach was developed by Riley and coworkers in 1992 (17). Since then, several T.vaginalis-specific assays have been described. Among the PCR targets are the ferredoxin gene $(17,8)$, highly repeated DNA sequences (11), the family of adhesion proteins (1), ß-tubulin gene (13), and 18S ribosomal gene (15). A real-time TaqMan-based detection of ferredoxin gene was designed and evaluated in 2001, using a previously described set of primers in conjunction with a novel, doublelabeled fluorescent probe (9). Later, an existing PCR method for ß-tubulin gene was adapted into a real-time PCR assay based on fluorescence resonance energy transfer (FRET) probe (6). Epidemiological data of this curable disease are scarce for Italy.

The prevalence of Trichomonas vaginalis infection was $4.2 \%$ in 15,213 infections of the cervicovaginal tract reported in Italy in the period September 1990-December 1999 (4) and it was $5.0 \%$ in 861 Italian female teenagers affected by STDs in the period September 1990-December 1997 (5).

In order to contribute to this promising line of evolution in diagnostic parasitology, and hoping to ease an epidemiologic investigation in our area, we developed an original real-time PCR TaqManbased technique. Since in the last few years there have been several reports concerning nucleic acid amplification-based approach, but this has never reached a wide acceptation, the aim of the present study was to investigate the effectiveness of the approach to the diagnosis of T.vaginalis infection by means of a molecular method. Compared to the traditional techniques, it was reasonable to expect an increase in the diagnostic accuracy by using a PCR procedure. Moreover, a step was done toward the exploitation of the potential to furnish quantitative information residing in real-time PCR. Indeed, in several instances concerning the infectious diseases the quantitative assay of the infecting agent is often predictive of the clinical context. In order to achieve this target, a calibration curve was set up. Moreover, to assess the adequacy of the pathologic sample, an endogenous DNA sequence (part of the $ß$-globin gene) (2) was amplified within the same reaction tube for each sample, as an inner control.

\section{MATERIALS AND METHODS}

\section{Patient population, sample collection, and dia- gnostic tests}

The population sample under study was formed by 583 consecutive adult female patients presenting at the Microbiology and Virology Service of Padua's Hospital, during the period January 2005December 2005. All had symptoms or personal history pointing to a possible genital infection. Three vaginal swabs were collected from each patient under speculum control. One swab was employed for wet mount microscopy, one for broth culture, and one for molecular approach. Trichomonas vaginalis was identified by means of a real-time PCR TaqMan. As a gold standard, the protozoan search was done by broth culture. Moreover, a microscopic wet mount search was performed.

\section{Broth culture}

The composition of the medium, Trichomonas Selective Broth (Labobasi srl, Milano, Italy) was peptone, liver extract, yeast extract, maltose, agar, chloramphenicol, methilene blue, horse serum. The culture was done by inoculating the swab into the broth and by incubating it at $37^{\circ} \mathrm{C}$ up to five days. The culture fluid was microscopically examined (magnification 40x) daily.

Identification of $T$. vaginalis was achieved by observation of motile organisms in wet-mount preparations.

\section{Wet mount microscopy}

By one hour from the collection of the samples, one vaginal swab for each patient was inoculated into $1 \mathrm{ml}$ of physiologic solution. Then, one drop of this solution was examined by microscopy (magnification 40X) in order to detect T.vaginalis by this characteristic shape and motility.

\section{DNA processing and TaqMan real-time PCR method}

After collection, the swab for molecular approach was eluted in $1 \mathrm{ml}$ of physiologic solution. 
The eluate was centrifuged at $8,500 \mathrm{rpm}$ for 5 minutes. The pellet was suspended in $400 \mathrm{ml}$ of saline and divided in two equal aliquots, one of which was submitted to DNA extraction, the other was stored at $-80^{\circ} \mathrm{C}$. The DNA, extracted by proteinase $\mathrm{K}$ and phenol-chloroform method, was resuspended in $100 \mu \mathrm{l}$ of water and stored at $20^{\circ} \mathrm{C}$ until use. Primers and probe sequences were selected from the ß-tubulin gene. The forward (TricF) and reverse (TricR) primer sequences are (5'-CACTCAAGCTCACAACACCAACA-3') and (5'-TGCCGGACATAACCATGGA-3') respectively. The minor groove binder probe TricP (5'-ACGGCGATCTTAAC-3') contained a fluorescent reporter dye (6-carboxy-fluorescein, FAM) at the 5'-end. The reaction was performed in a final volume of $50 \mu \mathrm{l}$ containing $5 \mu \mathrm{l}$ of DNA solution, $600 \mathrm{nM}$ TricF, $600 \mathrm{nM}$ TricR, $200 \mathrm{nM}$ TaqMan Probe, and $25 \mu \mathrm{l}$ TaqMan Universal PCR Master Mix (Applied Biosystems, Foster City, CA). Real-time PCR reaction was carried out with the ABI PRISM 7900 HT sequence detection system according to the following program: one cycle of $95^{\circ} \mathrm{C}$ for $10 \mathrm{~min}$, followed by 45 cycles each of $95^{\circ} \mathrm{C}$ for $15 \mathrm{~s}$ and $60^{\circ} \mathrm{C}$ for $1 \mathrm{~min}$.

A 66 bp PCR fragment obtained by amplification of a Trichomonas vaginalis positive sample with TricF and TricP primers was ligated into the pGEM-T Easy vector (Promega Corporation, USA), according to the manufacturer's instruction, and sequenced on both strands. Ten-fold serial dilutions from 10 to $10^{6}$ copies of the resulting plasmid, pTA-TRIC, were used in duplicate to generate a calibration curve for quantification of the protozoan load in clinical samples. The procedure appeared capable to detect the target copies in the range 10 to $10^{6}$. To rule out false negative results due to the presence of amplification inhibitors or poor quality of DNA extraction, an endogenous DNA sequence (part of the ß-globin gene) was amplified within the same reaction tube for each sample, as an inner control. The system for ß-globin sequence was as described before (2) with some modifications; the reporter moiety for the inner probe was VIC dye and the quencher was TAMRA (6-carboxytetramethylrhodamine).

\section{Statistical evaluation}

When the results of the diagnostic tests were expressed as dichotomous variables and compared to a dichotomous gold standard, sensitivity, specificity, positive predictive value and negative predictive value were calculated. The positivity rates, and the risk ratio indicting the increase of risk of a positive result due to the condition of immigrant, were also calculated, as the related p-value obtained by means of the $\chi 2$ test. In order to investigate the compromise between sensitivity and specificity, by exploiting the quantitative information residing in real-time PCR, a ROC (receiver operator characteristic) curve analysis was performed. As gold standard, again, the liquid culture test was employed. This was challenged against the protozoan load. To do it, the number of genomic copies of T.vaginalis per reaction tube was adjusted to 100,000 human nucleated cells, as detected by the ß-globin copy number.

\section{RESULTS}

Of the 583 patients submitted to investigation, 106 were immigrants aged 22 - 46 (median age: 28 years) and 477 born in Italy (natives aged 19-67; median age: 35 years). The prevalent cases of Trichomonas vaginalis infection were 22 by realtime PCR, 18 by microscopy, and 19 by culture. The accuracy indexes (gold standard: culture) are reported (Table 1), including positive and negative predictive values. The prevalence was 3.8\% (realtime PCR), 3.1\% (microscopy), 3.3\% (culture). The proportions of T.vaginalis positive patients for each diagnostic test within the two populations (immigrants and natives) are reported (Table 2) along with the relative risks (RR). The significance of the risk imposed by the immigrant condition was evaluated by use of $\chi^{2}$ test (highly significant). The range of the T.vaginalis genomic copy number per reaction in positive PCR patients was 11$1,720,751$, median: 210,129. The range of the adjusted copy number per 100,000 human nucleated cells was $84-3.72 \times 10^{7}$, median: $1,039,181$ (Figure 1 ). An adjusted copy number $>10,900$ predicted perfectly a positive culture. The ROC curve method showed a ROC area of 1.0 (95\% confidence interval 1.0-1.0) (Figure 2), pinpointing an ideal behavior for the assay test under evaluation.

\section{DISCUSSION}

We had the opportunity to collect the relevant casuistic at the Clinics for STDs outpatients, part of the Service of Microbiology and Virology of the Padua's Azienda Ospedaliera. The feasibility of the study was increased by the facilities concerning the technology of molecular diagnostic medicine, connected to the University Department of Histology, Microbiology and Medical Biotechnology. The method developed by our group was designed to target a well known gene, ß-tubulin. Primers were selected in order to amplify a shorter stretch of DNA (66 bp) than in a former system (13), aiming at a more efficient duplication process. Nonetheless, the specificity for T.vaginalis was maintained, as confirmed by comparing the amplicon with a gene bank. 
In order to obtain a quantitative assay of the protozoan load, a procedure based on interpolation with a calibration curve was set up. Another enhancement with respect to the methods published formerly was the addition of an inner standard, a real-time PCR amplification system targeted to a human gene, ß-globin. This was co-amplified within the same reaction tube. So doing, the adequacy of the sample and the possible presence of inhibitors were routinely assessed, easing the conversion of the assay into a quantitative molecular detection. In this context, the present paper is the first report on a quantitative real-time PCR detection of T.vaginalis in clinical samples. The molecular approach resulted to be very accurate. Three apparent false positives by real-time PCR probably reflected a superior sensitivity compared to culture. Ease of execution and short processing time were additional advantages. The accuracy of the method confirms previous reports based on real-time PCR methods $(9,6)$. The quantitative potential of the TaqMan method was also docu- mented. The prevalence of Trichomonas vaginalis in the population presenting at our diagnostic center was reliably evaluated. By real-time PCR the prevalence of $T$. vaginalis in the female population was $17.9 \%$ (immigrants), $0.6 \%$ (natives), and $3.8 \%$ (overall). The present report is the largest evaluation of the prevalence of the infection done in Italy with the aid of the most accurate diagnostic tool presently available. Moreover, the risk factor weighing on the immigrant population is apparent.

In conclusion, the target of confirming the effectiveness of the molecular approach was achieved. The real-time PCR was clearly the most accurate way to detect the protozoon. The method appears to be feasible and convenient in a busy laboratory, provided the necessary equipment is available. Moreover, our real-time PCR is likely to be suitable also to urethral swabs of male patients. Because of difficulties with diagnosing trichomoniasis in men, the implementation of a molecular method to detect Trichomonas vaginalis could

Table I. Sensitivity, specificity, PPV and NPV of real-time PCR and microscopy

\begin{tabular}{lllll}
\hline & Sensitivity & Specificity & PPV & NPV \\
\hline real-time PCR & $100 \%$ & $99.5 \%$ & $86.4 \%$ & $100 \%$ \\
\hline Microscopy & $94.7 \%$ & $100 \%$ & $100 \%$ & $99.8 \%$ \\
\hline
\end{tabular}

The qualitative accuracy indexes are reported for two tests and for the overall, unsegmented population. The gold standard is liquid culture detection of Trichomonas vaginalis.

PPV: positive predictive value. NPV: negative predictive value

Table 2. Positivity for Trichomonas vaginalis in foreigners, natives, and overall casuistic

\begin{tabular}{|c|c|c|c|c|c|c|c|c|}
\hline & \multicolumn{2}{|c|}{ Immigrants } & \multicolumn{2}{|l|}{ Natives } & \multicolumn{4}{|l|}{ Overall } \\
\hline & positives & $\%$ & positives & $\%$ & positives & $\%$ & $\mathbf{R R}$ & p-value \\
\hline real-time PCR & 19 & $17.9 \%$ & 3 & $0.6 \%$ & 22 & $3.8 \%$ & 28.5 & $<0.000001$ \\
\hline microscopy & 14 & $13.2 \%$ & 4 & $0.8 \%$ & 18 & $3.1 \%$ & 15.7 & $<0.000001$ \\
\hline culture & 15 & $14.2 \%$ & 4 & $0.8 \%$ & 19 & $3.3 \%$ & 16.9 & $<0.000001$ \\
\hline
\end{tabular}

Risk ratios, indicating the increase of the base risk due to immigrant condition, and the related p-values, are indicated.

Data are stratified for the three diagnostic tests under scrutiny

$R R$ : Risk ratio

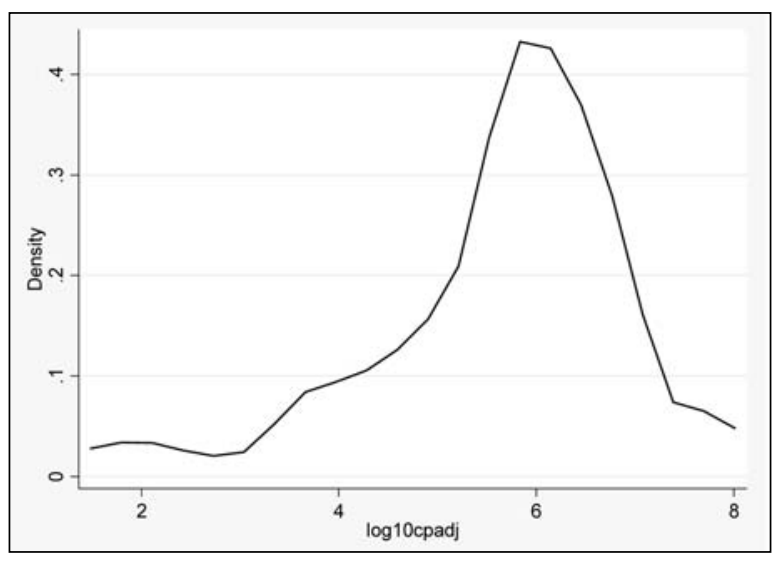

Figura I. Frequency distribution of the protozoan load in vaginal swabs. The Trichomonas vaginalis genomic copy number per reaction was adjusted for 100,000 human B-globin gene copy number in each vaginal swab; then, the data were $\log 10$-converted

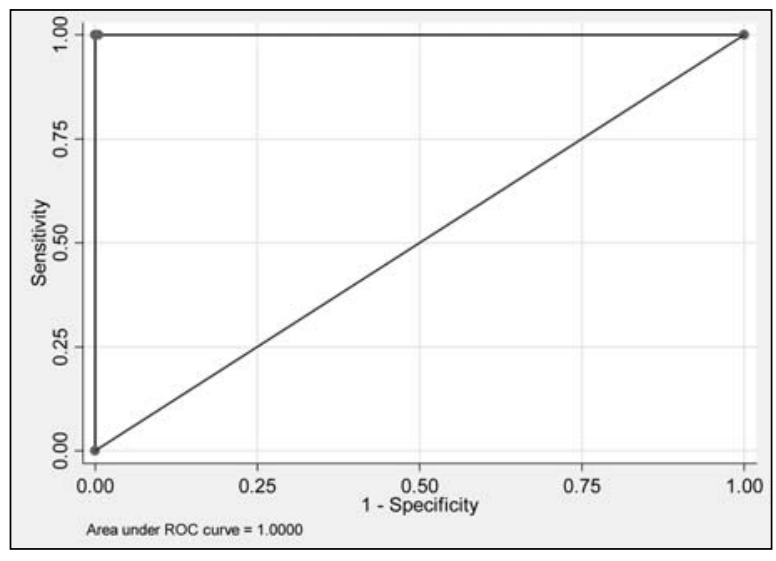

Figura I. ROC analysis. As gold standard the liquid culture test was employed versus the protozoan load in vaginal samples. ROC: receiver operator characteristic 
increase the reliability of estimates of prevalence of this infection in the male population. Indeed, the sensitivity of microscopic examination of wet mounts or cultures, for male samples, was reported to range from $60 \%$ to $80 \%$ (12), whereas the sensitivity of urethral swab culture or urine sample was $62.2 \%$ or $61.6 \%$, respectively (10). Moreover, the potential application of PCR to urine samples could avoid the urethral swab to male patients.

The present study also explored the potential of the technique as an epidemiological investigation tool, furnishing preliminary data on females in a local geographical context, situated on North East Italy.

\section{REFERENCES}

1. Alderete JF, O’Brien JL, Arroyo R, et al. Cloning and molecular characterization of two genes encoding adhesion proteins involved in Trichomonas vaginalis cytoadherence. Mol Microbiol 1995; 17: 69-83

2. Biasolo MA, Calistri A, Cesaro S, et al. Case report: Kinetics of Epstein-Barr virus load in a bone marrow transplant patient with no sign of lymphoproliferative disease. J Med Virol 2003; 69: 220-24

3. Cotch MF, Pastorek JG, Nugent RP, et al. Trichomonas vaginalis associated with low birth weight and preterm delivery. Sex Transm Dis 1997; 24: 361-62

4. Giuliani M, Suligoi B, Latino MA, Responsabili Centri di Sorveglianza Nazionale MST. Epidemiologia delle infezioni cervico-vaginali. In: Consultorio familiare. Giornata di aggiornamento. Volume degli atti. Bologna, 7 ottobre 2000. A cura di D. Nascetti. p. 11-20

5. Giuliani M, Suligoi B, Centri partecipanti alla Sorveglianza Nazionale delle MST. Sexually transmitted diseases and HIV-1 infection in Italian adolescents. Minerva Ginecol 2000; 52(Dec Suppl 1):14-18

6. Hardick J, Yang S, Lin S, et al. Use of the Roche LightCycler instrument in a real-time PCR for Trichomonas vaginalis in urine samples from females and males. J Clin Microbiol 2003; 41: 5619-22

7. Honigberg BM. Trichomonads parasitic in humans. Springer Verlag, New York, 1990
8. Jeremias J, Draper D, Ziegert M, et al. Detection of Trichomonas vaginalis using the polymerase chain reaction in pregnant and non-pregnant women. Infect Dis Obstet Gynecol 1994; 2:16-19

9. Jordan JA, Lowery D, Trucco M. TaqMan-based detection of Trichomonas vaginalis DNA from female genital specimens. J Clin Microbiol 2001; 39: 381922

10. Kaydos-Daniels SC, Miller WC, Hoffman I, et al. The use of specimens from various genitourinary sites in men, to detect Trichomonas vaginalis infection. JID 2004; 189: 1926-31

11. Kengne P, Veas F, Vidal N, et al. Trichomonas vaginalis: repeated DNA target for highly sensitive and specific polymerase chain reaction diagnosis. Cell Mol Biol 1994; 40: 819-31

12. Krieger JN, Verdon M, Siegel N, et al. Risk assessment and laboratory diagnosis of trichomoniasis in men. J Infect Dis 1992; 166: 1362-66

13. Madico G, Quinn TC, Rompalo A, et al. Diagnosis of Trichomonas vaginalis infection by PCR using vaginal swab samples. J Clin Microbiol 1998; 36:3205-10

14. Martin DH, Michael FR. Trichomonas vaginalis. In: Mandell GL, Bennett JE, and Dolin R , eds. Principles and Practice of Infectious Diseases. 6th edn. Churchill, Livingstone, New York, 2005: 320509

15. Mayta H, Gilman RH, Calderon MM, et al. 18S ribosomal DNA-based PCR for diagnosis of Trichomonas vaginalis. J Clin Microbiol 2000; 38: 2683-87

16. Rein MF, Müller M. Trichomonas vaginalis and trichomoniasis. In: Holmes KK, Mårdh PA, Sparling PF, Wiesner PJ, eds. Sexually transmitted diseases. New York, NY: McGraw-Hill Inc, 1990: 481-92

17. Riley DE, Roberts MC, Takayama T, et al. Development of a polymerase chain reaction-based diagnosis of Trichomonas vaginalis. J Clin Microbiol 1992; 30 (Suppl 2):465-72

18. Rubino S, Muresu R, Rappelli P, et al. Molecular probe for identification of Trichomonas vaginalis DNA. J Clin Microbiol 1991; 29: 702-06

19. Stary A, Kuchinka-Koch A, Teodorowicz A. Detection of Trichomonas vaginalis on modified Columbia Agar in the routine laboratory. J Clin Microbiol 2002; 40: 3277-80

20. World Health Organization. 1995. An overview of selected curable sexually transmitted diseases. In: World Health Organization editor. Global program on AIDS. World Health Organization, Geneva. Switzerland. p. 2-27 